\title{
Análise crítica da proposta de reforma da previdência social no Brasil entre os anos 2016 e 2018
}

\section{Critical analysis of the proposal for social security reform in Brazil between 2016 and 2018}

Mauri Antônio da Silva ${ }^{a}$

(D) http://orcid.org/0000-0001-6162-0148

Resumo: O objetivo geral deste trabalho foi a análise crítica da tentativa de contrarreforma da previdência que se materializou na Proposta de Emenda Constitucional n. 287/2016. A metodologia utilizada foi a pesquisa teórico-bibliográfica e o método foi o materialismo histórico. Os resultados da pesquisa mostraram que a ofensiva liberal conservadora pela retirada dos direitos previdenciários está relacionada aos interesses do capital financeiro para aumentar seus lucros à custa do Orçamento da União.

Palavras-chave: Crise do Capital. Financeirização. Reforma Previdenciária. Direitos Sociais.

\begin{abstract}
This article aims a critical analysis from social-security reform emerged from the Proposal of Constitutional Amendment $n^{\circ}$ 287/2016. The methodology used is based on theoretical-bibliographic research and the method is a historical materialism. The research results present that the conservative-liberal attack to remove the social-security rights is linked to financial interests to increase profit at the expenses of Union budget.
\end{abstract}

Keywords: Economic Crises. Financialization. Social-Security Reform. Social Rights. 


\section{Introdução}

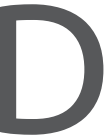

epois de vinte e um anos sob a ditadura civil-militar, o Brasil passou por um processo de redemocratização com a realização de uma Assembleia Nacional Constituinte (1987/1988). Na Constituição Federal de 1988, os constituintes asseguraram os direitos sociais como direitos fundamentais em seu Artigo $6^{\circ}$, constituindo as bases legais para o desenvolvimento de um novo marco civilizatório. A partir de então, ficou definido que são direitos sociais constitucionalizados a educação, a saúde, a alimentação, o trabalho, a moradia, o lazer, a segurança, a previdência social, a proteção à maternidade e à infância, a assistência aos desamparados (Brasil, 2002).

No Artigo 194 foi estabelecido que "a Seguridade Social compreende um conjunto integrado de ações de iniciativa dos poderes públicos e da sociedade, destinadas a assegurar os direitos relativos à saúde, à previdência e à assistência social", tendo como objetivos: a universalidade do atendimento; a uniformidade e equivalência dos benefícios e serviços às populações urbanas e rurais; a seletividade e distributividade na prestação dos benefícios e serviços; a irredutibilidade do valor dos benefícios; a equidade na forma de participação no custeio; a diversidade das fontes de financiamento e a participação democrática da comunidade em sua gestão (Brasil, 2002).

Ressalte-se que o legislador constituinte originário foi motivado pela preocupação em estabelecer um modelo de seguridade social que tem por objetivo a garantia de uma série de direitos sociais ao trabalhador, na perspectiva da construção de um Estado Social, tendo por inspiração os modelos de Estados de Bem-Estar europeus.

Desde o início dos anos 1990, esses direitos sociais foram limitados pela hegemonia do capital financeiro na economia brasileira, por meio das contrarreformas do Estado brasileiro, com fortes consequências sobre a Previdência Social. As reformas previdenciárias, estimuladas pelo Banco Mundial e o Fundo Monetário Internacional, reduziram o alcance dos direitos sociais estabelecidos na Constituição Federal, constituindo-se em verdadeiras contrarreformas, considerando que existe uma forte evocação do passado no pensamento neoliberal, além de um aspecto realmente regressivo "nas condições de vida e de trabalho das maiorias” (Behring, 2008, p. 57). 
Num contexto de forte crise econômica da economia brasileira, o governo Temer encaminhou, ao final de 2016, uma nova proposta de contrarreforma da previdência social para atender aos interesses do capital financeiro, interessado em reduzir os recursos do orçamento da União para as políticas sociais e ampliar os recursos para remuneração dos juros e encargos da dívida pública. Neste artigo, sustento a hipótese de que a Proposta de Emenda Constitucional (PEC) n. 287, de dezembro de 2016, que trata da reforma da Previdência e da Assistência Social, faz parte de uma estratégia de manutenção dos ganhos do capital financeiro, que se apropria de uma parcela extraordinária do orçamento público, por meio do sistema da dívida pública.

Além dessa Introdução, o texto é desenvolvido em duas seções. A primeira se intitula "Financeirização e regressão social", e a segunda, "A Proposta de Reforma da Previdência e da Assistência Social do Governo Temer". Ao final, apresento a Conclusão.

\section{Financeirização e regressão social}

A financeirização mundial faz parte da atual fase do capitalismo que se iniciou durante a crise global dos anos 1970 para a acumulação de riquezas baseado no excessivo poder do setor financeiro mundial ${ }^{1}$. Esse poder do capital financeiro se consolidou pela expansão extraordinária de instrumentos financeiros, gerados principalmente por dívidas sem a correspondente entrega de recursos, emissão de títulos, moeda e de produtos financeiros sem respaldo, usualmente chamados de "tóxicos" (Fatorelli, 2013).

Como os capitalistas financeiros apropriam-se de parte do lucro originado nos investimentos produtivos por meio da exploração da força de trabalho em escala global, quanto maior essa sede de lucro do capital financeiro maior será a exploração dos trabalhadores na esfera da produção, pois o capitalista buscará compensar suas perdas com o pagamento de juros através da redução dos salários dos trabalhadores e da intensificação do trabalho (Chesnais, 1996; Marx, 2012).

O predomínio do capital financeiro na economia resulta no aumento das desigualdades econômicas e sociais, sobretudo em tempos de manifestação das crises capitalistas (Harvey, 2011). 
Na década de 1980, os Estados Unidos da América do Norte, o Banco Mundial e o Fundo Monetário Internacional (FMI) passaram a preconizar reformas neoliberais para os países latino-americanos, que foram denominadas de Consenso de Washington (Soares, 2003). Nos anos 1990, essas reformas liberais e conservadoras foram implantadas no Brasil, conduzindo a um amplo processo de privatização de empresas públicas, que tinham sido fundamentais no desenvolvimento industrial e econômico do país, envolvendo diversos setores e serviços estratégicos controlados pelo Estado, como telecomunicações e energia elétrica (Cano, 2000). A orientação dos programas de ajuste estrutural visava mudar a orientação do Estado, aumentando os subsídios para o capital e diminuindo os investimentos em serviços sociais (Petras, 1999).

As políticas neoliberais aprofundaram o processo de captura do Estado brasileiro pela burguesia financeira por meio dos seus órgãos associativos de classe que organizavam suas demandas junto ao Estado (Minella, 1997). Uma estrutura legal foi instituída para consolidar esse controle, tal como a Lei de Responsabilidade Fiscal (LRF); as Metas de Superávit Primário; uso de recursos das privatizações para o pagamento da dívida; e Disposições Constitucionais, como o Artigo 166, parágrafo 3ㅇ, II, b, que exclui os gastos com dívida financeira pública da regra geral aplicada aos demais gastos públicos. Isto é, no caso desse tipo de gasto não se faz necessário indicar ou definir a fonte dos recursos, no momento da elaboração orçamentária da União (Brasil, 2002; Fatorelli, 2013).

O orçamento público é um espaço de luta política, onde as diferentes forças da sociedade buscam assegurar a satisfação de seus interesses (Salvador, 2010). No Brasil, o fundo público ganhou contornos restritivos, tanto pela ótica do financiamento como pela dos investimentos sociais. Este país latino-americano, com imensas riquezas naturais, ficou muito longe das já limitadas conquistas da social-democracia ocorridas nos países desenvolvidos. O fundo público que poderia ser utilizado para diminuir as desigualdades sociais vem sendo aprisionado pelo capital financeiro. Em 2008, em meio a uma crise capitalista internacional, cerca de 70 bilhões foram desviados para o capital financeiro, por meio da Desvinculação das Receitas da União - DRU e por incentivos fiscais aos empresários (Salvador, 2012).

Segundo Sader (2016, p. 22), durante os governos de Lula e Dilma, em lugar dos tratados de livre-comércio, o Brasil priorizou as políticas de 
integração regional e o intercâmbio Sul-Sul, redirecionando o comércio internacional do Brasil e a sua inserção no mundo. Dilma Rousseff tentou no segundo mandato baixar as taxas de juros, mas, sob duros ataques da mídia, recuou. Atualmente o país vive uma combinação perversa de estagnação com inflação, com altas taxas de juros, na contramão dos países que combatem a crise com taxas de juros de até mesmo 0\% (Sader, 2016, p. 24).

Os estudos da Auditoria Cidadã da Dívida sobre o Orçamento Geral da União (Executado em 2015), conforme o Gráfico 1, mostram o privilégio dado ao capital financeiro. Em 2015, se gastou 42,43\% do orçamento da União com

Gráfico 1. Orçamento Geral da União (Executado em 2015) - Total = R\$ 2,268 trilhões

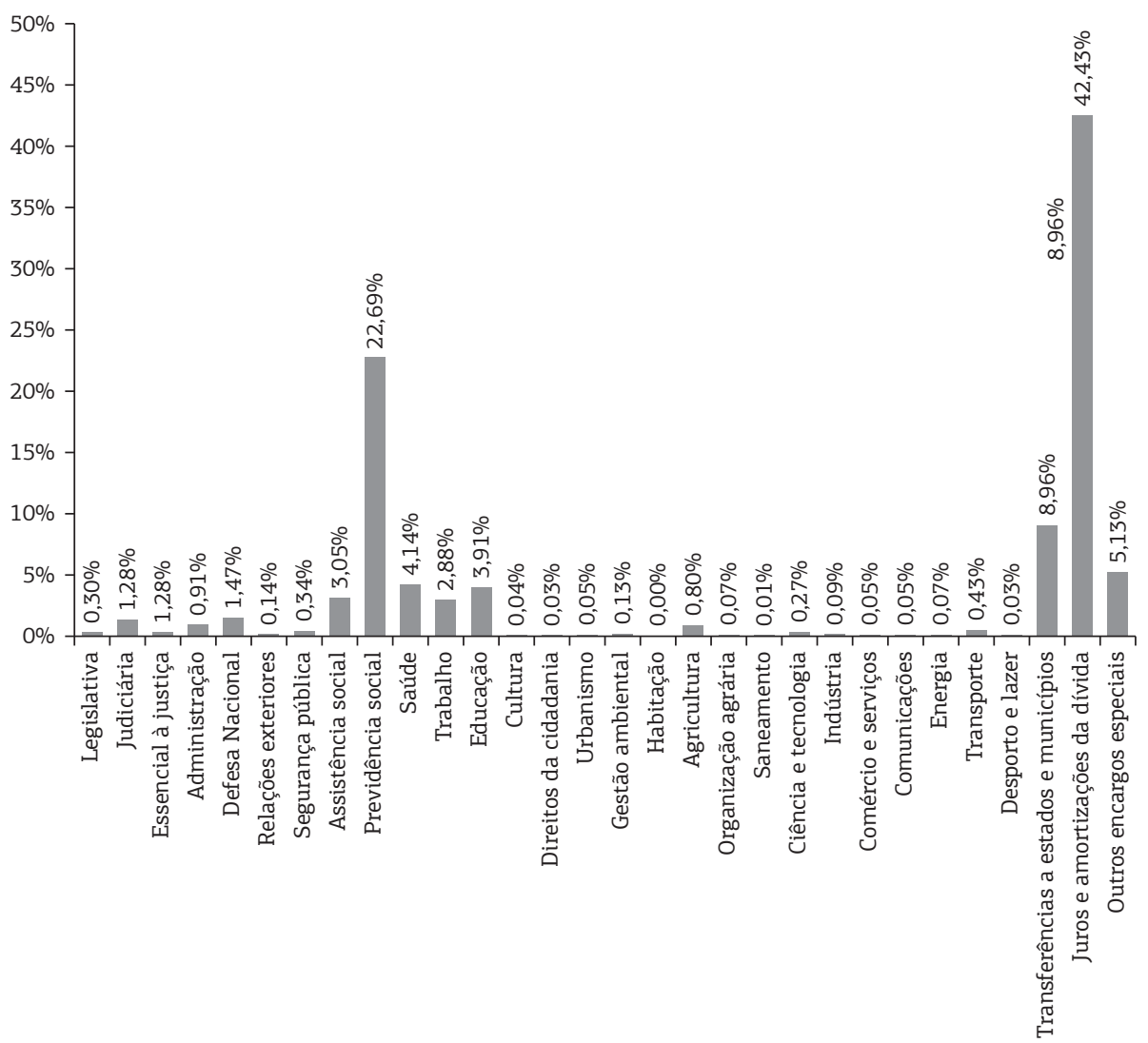

Fonte: Auditoria Cidadã da Dívida (2015). 
juros e amortizações da dívida. Verifica-se, ainda, como essa opção resulta em baixo investimento em políticas sociais. Na saúde, o governo gastou $4,14 \%$ do orçamento, e na educação, 3,31\%. A política previdenciária ficou com 22,6\%.

\section{A Proposta de Reforma da Previdência e da Assistência Social do Governo Temer}

Após o impeachment, consumado em 31 de agosto de 2016, contra o mandato democrático da presidenta Dilma Rousseff, os ataques aos direitos sociais, que se inserem na ofensiva neoliberal iniciada mundialmente nos anos 1970, em resposta à crise estrutural do capital, ressurgiram com força num cenário de desaceleração econômica da economia brasileira, desde o ano de 2014, quando a opção pela austeridade econômica foi apresentada por economistas neoliberais como uma saída para a crise (Singer, 2016).

Para o pensamento conservador, era necessária uma política econômica mais austera, que fosse capaz de desaquecer a economia, através da diminuição do consumo, dos salários e do gasto público, e elevar a taxa de desemprego, "criando assim cenário favorável para o recuo da inflação, aproximando-a do centro do regime de metas", e ao fim e ao cabo, "o crescimento econômico seria retomado, uma vez que o aumento da confiança dos agentes econômicos impulsionaria o consumo e os investimentos privados" (DIEESE; ANFIP, 2017, p. 13). Para pavimentar esse caminho foram cortados os gastos públicos, inclusive as políticas sociais e os investimentos. A política monetária foi marcada pelo aumento das taxas de juros e pela restrição severa do crédito, que contribuíram para transformar uma desaceleração em uma depressão econômica, com graves consequências sociais.

Segundo o Dieese e a Anfip (2017, p.12) o Produto Interno Bruto (PIB) caiu 3,8\% em 2015 e 3,49\% (estimativa) em 2016. Uma queda por dois anos consecutivos que é inédita na série histórica do IBGE. E mais, um aumento abrupto de impostos e tarifas públicas, no final de 2014, em uma situação de rápida desvalorização cambial, impulsionou as taxas de inflação, que quase dobraram de tamanho ao longo de 2015. A taxa de desemprego, por sua vez, conforme a Pesquisa Nacional por Amostra de Domicílios (Pnad 
Contínua) do IBGE, avançou de 6,5\% no último trimestre de 2014, para $11,8 \%$ no terceiro trimestre de 2016. A dívida pública acelerou a sua trajetória de crescimento, passando de aproximadamente 56,0\% do PIB ao fim de 2014 para mais de 70,0\% em 2016.

A principal causa da crise não são os direitos sociais, como defendem os economistas conservadores, mas sim a apropriação do fundo público pelo capital financeiro. Para o Dieese e a Anfip (2017, p. 14) a austeridade econômica piorou de forma generalizada os principais indicadores econômicos do país. $\mathrm{O}$ desajuste fiscal é de natureza essencialmente financeira, como consequência dos juros altos e das inconsistências do regime fiscal e macroeconômico.

A proposição da contrarreforma da Previdência se articula com a Proposta de Emenda Constitucional n. 95/2016² que instituiu o "Novo Regime Fiscal", originado pelas críticas liberais e conservadoras ao modelo social da Constituição Federal de 1988 (DIEESE, 2016), e com a ampliação da desvinculação de recursos constitucionais garantidos para os investimentos sociais. O Congresso Nacional aprovou em 2016 a ampliação de 20\% para 30\% da Desvinculação de Receitas da União (DRU) (DIEESE; ANFIP, 2017).

A Emenda Constitucional n. 95/2016 congela os investimentos sociais por 20 anos, limitando seus reajustes a variação do Índice de Preços ao Consumidor Amplo (IPCA), numa inédita regressão social estabelecida no país, tendo em vista o cenário de crescimento de $9 \%$ da população e de aumento significativo dos idosos, que trará demandas crescentes ao sistema de seguridade social (Salvador, 2016)3. A Emenda estabeleceu para os próximos 20 anos, o teto dos gastos públicos primários, isto é, de todas as despesas governamentais, exceto das financeiras que estão voltadas para o pagamento dos encargos e serviços da dívida.

2 BRASIL. Emenda constitucional n. 95. Altera o Ato das Disposições Constitucionais Transitórias, para instituir o Novo Regime Fiscal, e dá outras providências. Senado Federal. Secretaria de Informação Legislativa. Disponível em: <http://legis.senado.leg.br/legislacao/ListaTextoIntegral.action?id=251058\&norma=270459>. Acesso em: 8 fev. 2017.

3 Ver JACOULD (2017). Sobre a inconstitucionalidade do NRF ver VIEIRA JÚNIOR (2016). Disponível em: <http://www12.senado.leg.br/publicacoes/estudos-legislativos/tipos-de-estudos/ boletins-legislativos/bol53>. 
Ao final de 2016, foi enviado ao Congresso Nacional a Proposta de Emenda Constitucional n. 287 (PEC n. 287/16), que trata da Previdência e da Assistência Social, e afetará o direito de milhões de brasileiros a uma aposentadoria digna e aos benefícios assistenciais, como tem ocorrido em todas as reformas realizadas desde a década dos anos 1990, que revelam o seu "distanciamento da seguridade social e o fortalecimento da visão de seguro", inclusive, com o "fortalecimento das entidades de previdência complementar abertas e fechadas" (Silva, 2015, p. 139) ${ }^{4}$.

Com a possibilidade de aumentar as dificuldades para os trabalhadores poderem se aposentar aumentou a procura por planos privados de aposentadoria geridos por grandes instituições financeiras. Um levantamento realizado pela Fenaprevi (Federação Nacional de Previdência Privada e Vida), observou uma alta de 19,93\% na contratação dos planos privados em 2016 (Silva, 2018).

Uma consequência das reformas neoliberais foi o achatamento do benefício previdenciário por meio da instituição do fator previdenciário ${ }^{5}$ que força o trabalhador a trabalhar mais tempo para obter uma melhor aposentadoria. No Brasil, são 5,7 milhões de aposentados (28,14\% do total) entre os 20,3 milhões de aposentados que continuam exercendo atividades laborais (Fazio, 2016).

A justificativa do Governo Federal para defender a reforma se ancora na tese de que a Previdência Social brasileira se tornou insustentável financeiramente, apresentando sucessivos déficits orçamentários, sendo necessárias medidas para garantir sua sustentabilidade através do "aperfeiçoamento de suas regras". O Governo Federal entende como principal causa dessa "crise de financiamento” as mudanças demográficas na população brasileira,

4 BRASIL. Proposta de Emenda à Constituição n. 287/2016. Altera os arts. 37, 40, 109, 149, 167, 195, 201 e 203 da Constituição, para dispor sobre a seguridade social, estabelece regras de transição e dá outras providências. Brasília: Câmara dos Deputados, 2016. Disponível em: $<$ http://www.camara.gov.br/proposicoesWeb/prop_mostrarintegra?codteor=1514975\&filena me=PEC+287/2016>. Acesso em: 8 dez. 2016.

5 O fator previdenciário é tanto maior quanto maior forem a idade e o tempo de contribuição do segurado e quanto menor for a expectativa de vida do segurado na época da concessão da aposentadoria por tempo de contribuição (ATC) (Lei n. 9.876, de 26 nov. 1999). 
sobretudo o envelhecimento populacional. Além disso, afirma que existem algumas distorções e inconsistências do modelo previdenciário brasileiro, que criariam diferenciações entre os modelos do Regime Geral da Previdência Social (RGPS) e dos Regimes Próprios de Previdência Social (RPPSs) e entre os diversos segmentos da população. A proposta também altera regras da Assistência Social, reduzindo a rede de proteção social constituída nas últimas décadas (DIEESE, 2017, p. 2).

O governo não faz referência aos gastos com juros sobre a dívida pública que, em 2015 (R\$ 502 bilhões), foram maiores que os gastos previdenciários ( $\mathrm{R} \$ 486$ bilhões); às desonerações tributárias que somaram $\mathrm{R} \$ 280$ bilhões em 2015 (o governo federal abre mão de cerca de $20 \%$ das suas receitas); e ao fato de que anualmente o governo deixa de recolher cerca de $\mathrm{R} \$ 452$ bilhões (2015), por falta de estruturas de combate mais efetivas à sonegação fiscal ${ }^{6}$.

Quanto ao suposto déficit, o fato é que a Seguridade Social é financiada por contribuições sociais previstas na Constituição, para garantir os direitos de previdência, saúde e assistência social de todos os cidadãos. As análises criteriosas da economista Denise Lobato Gentil mostram que a Seguridade Social é superavitária. O superávit estimado com base em dados das receitas e despesas do governo foi de 56,7 bilhões de reais em 2010, 78,1 bilhões em 2012, 56,4 bilhões em 2014, e 20,1 bilhões em 2015 (Drummond, 2016).

As receitas da Seguridade Social compreendem a Contribuição Social para o Financiamento da Seguridade Social (COFINS); a Contribuição Social sobre o Lucro Líquido das Empresas (CSLL); o Programa de Integração Social (PIS) e o Programa de Formação do Patrimônio do Servidor Público (Pasep); impostos sobre exportações; impostos sobre as loterias, entre outros.

$\mathrm{Na}$ verdade, sobram recursos que são desviados para a aplicação em outras finalidades do governo. A Desvinculação das Receitas da União (DRU), criada pelo Governo Cardoso na década de 1990, desviava 20\% do orçamento da Seguridade Social para garantir a sobra de recursos orçamentários para

6 Para maiores detalhes sobre a sonegação fiscal, ou seja, dos montantes devidos e não recolhidos, que contribuem para deteriorar os resultados financeiros da Previdência e da Seguridade Social, ver CPIPREV (2017). 
o pagamento dos serviços da dívida pública brasileira. Em 2016, por meio de uma alteração da lei, o governo prorrogou a vigência da DRU até 31 de dezembro de 2023 , e ampliou para $30 \%$ o percentual do orçamento que pode remanejar livremente (Salvador, 2016).

A Proposta de Emenda Constitucional n. 287/2016, em sua versão original, promove o endurecimento das regras de acesso aos benefícios da Previdência e da Assistência Social. Entre as principais alterações estão: extinguir a aposentadoria por tempo de contribuição; estabelecer uma idade mínima única para aposentadoria (aos 65 anos) para praticamente todo o conjunto dos trabalhadores (urbanos e rurais; do setor público e do privado; professores; homens e mulheres); ${ }^{7}$ mudar o cálculo e reduzir o valor dos benefícios previdenciários em geral; proibir acúmulo de benefícios, como pensões e aposentadorias; e desvincular benefícios assistenciais e pensões do salário mínimo. Essas alterações promovem o rebaixamento no valor médio dos benefícios, minimizando o alcance e a importância da Previdência pública, que é constituída pelo Regime Geral da Previdência Social (RGPS) e os Regimes Próprios de Previdência Social (RPPSs), e da Assistência Social (DIEESE, 2017; Fazio, 2016).

A PEC n. 287 estabelece que a concessão da aposentadoria passa a requerer do segurado pelo menos 65 anos de idade e o mínimo de 25 anos de contribuição mensal (o correspondente a 300 contribuições). Isso é uma regra geral tanto para o RGPS quanto para os RPPSs. Caso a PEC seja aprovada, essas regras passam a ser aplicadas a todos os futuros ingressantes no mercado de trabalho brasileiro e aos trabalhadores (do sexo masculino) com idade inferior a 50 anos e às trabalhadoras com menos de 45 anos de idade. Desse modo fica extinta a aposentadoria por tempo de contribuição de 35 anos.

A PEC n. 287 propõe que o valor do benefício de aposentadoria passe a ser equivalente a $51 \%$ do salário de benefício mais um ponto percentual a cada ano de contribuição, limitado a 100\% do salário de benefício

Atualmente, existem três tipos de aposentadoria no sistema previdenciário brasileiro: por idade, por tempo de contribuição e por invalidez. 
e ao teto do RGPS. Para a aposentadoria, continua vigorando o piso de um salário mínimo ${ }^{8}$. Em síntese, a PEC n. 287 reduz o patamar inicial do valor da aposentadoria como percentual do salário de benefício de $70 \%$ para $51 \%$ e impõe o teto de $100 \%$ do salário de benefício para todos os contribuintes. Com essa fórmula, o trabalhador brasileiro terá que trabalhar 49 anos ou quase meio século para poder ganhar uma aposentadoria integral (DIEESE, 2017).

A contrarreforma desestrutura o modelo de proteção social brasileiro, que beneficia 24,5 milhões de aposentados e pensionistas, entre os quais, 8,6 milhões vivem no campo, e dois terços recebem apenas um salário mínimo por mês (Drummond, 2016).

A equiparação entre trabalhadores urbanos e rurais desconsidera as enormes diferenças das condições de trabalho no campo e na cidade. A proposta desconsidera também as especificidades da inserção das mulheres no trabalho assalariado. Os estudos mostram que $70 \%$ da extrema pobreza se concentra na zona rural do Nordeste, não se justificando que se aplique de modo uniforme os mesmos critérios de aposentadoria que são aplicados em países desenvolvidos (Fagnani, 2016).

Entre outras mudanças previstas estão a proibição de acumulação de aposentadorias, com exceção das já previstas em lei, e o fim da paridade e a integralidade para todos os funcionários públicos que não tenham o direito adquirido na data da promulgação da Emenda pela Presidência da República (Queiroz, 2016).

Os benefícios sociais poderão sofrer um profundo retrocesso. Atualmente, o Benefício de Prestação Continuada da Lei Orgânica da Assistência Social (BPC-LOAS), paga um salário mínimo mensal ao idoso com mais de 65 anos ou a pessoa que tem deficiência física, mental, intelectual ou sensorial de longo prazo. Ambos devem pertencer a famílias com uma renda per capita inferior a 1/4 do salário mínimo vigente (Lei n. 8.742/1993 com a redação dada pela

8 A PEC n. 55, aprovada em turno final no dia 13 de dezembro de 2016 e promulgada como Emenda Constitucional n. 95, abre a possibilidade de não concessão de aumento real ao salário mínimo, caso as despesas primárias ultrapassem o teto imposto a elas pela variação da inflação. 
Lei n. 12.435/2011)9. Segundo a proposta inicial do governo, o benefício será desvinculado do salário mínimo. A idade mínima passará de 65 para 70 anos, e será pago à pessoa cuja renda familiar per capita seja inferior a um valor a ser ainda definido em lei. Ou seja, poder-se-á estabelecer um valor ainda inferior ao atual, impossibilitando aos pobres de terem uma renda garantida pelo Estado.

Com a pressão dos empresários sobre o governo e a Câmara dos Deputados a reforma da Previdência e da Assistência Social (PEC n. 287/16) foi aprovada na Comissão Especial, no dia 9 de maio, em forma de substitutivo. Em seguida, foi enviada para ser votada em dois turnos, no plenário da Câmara.

Entre as principais mudanças relacionadas à proposta inicial está a mudança na Constituição da diferença de idade para aposentadoria entre homens e mulheres (mas não em todos os casos). A idade mínima foi estabelecida em 62 anos para a mulher e 65 anos para o homem, na regra permanente. Nas regras de transição, foi mantida a idade de 55 e 60 anos para os servidores públicos, e 53 anos para a mulher e 55 anos para o homem, no Regime Geral da Previdência Social. Foi mantido o direito dos trabalhadores rurais ao benefício de 1 Salário Mínimo com idade menor (57 anos para as mulheres, 60 para os homens), mas desde que comprove 15 anos de contribuição. Passa a exigir 40 anos de contribuição, e não mais 49 anos, para a aposentadoria "integral". Ficou também garantido que nenhum benefício de pensão ou assistência social será inferior ao Salário Mínimo (SM), afastando, desse modo, a ameaça do rebaixamento do BPC e das pensões (Santos, 2017).

Aspectos problemáticos da proposta original foram mantidos, ou até mesmo agravados, no texto aprovado pela Comissão Especial, podendo-se citar, entre outros: a manutenção de idade mínima elevada para a aposentadoria, com o fim da aposentadoria por tempo de contribuição; a manutenção da carência de 25 anos; o aumento da idade da mulher para a aposentadoria

$9 \quad$ BRASIL. Presidência da República - Casa Civil - Subchefia para Assuntos Jurídicos. Lei Orgânica da Assistência Social. Disponível em: <http://www.planalto.gov.br/ccivil_03/leis/ L8742compilado.htm>. Acesso em: 7 dez. 2016. 
rural de 55 para 57 anos; manutenção da contribuição individual sobre o Salário Mínimo para os trabalhadores rurais que sobrevivem da economia familiar e a manutenção de restrições para uso de tempo rural em aposentadoria urbana (Santos, 2017).

Observa-se que frente à mobilização de centrais sindicais, partidos de oposição, e movimentos sociais contra a proposta, os parlamentares aliados ao governo fizeram pequenas concessões, mas mantiveram o seu caráter regressivo contra as condições de vida das classes subalternas ${ }^{10}$.

Em 22 de novembro de 2017, o governo apresentou um novo texto à reforma da Previdência, seguindo a premissa de que é "melhor alguma reforma, do que reforma alguma". O texto foi apresentado aos deputados por Arthur Maia (PPS-BA), relator da reforma da Previdência, durante jantar com o presidente Michel Temer no Palácio da Alvorada, numa tentativa de votar a matéria, em $1^{\circ}$ turno, até o dia 6 de dezembro.

De acordo com o Diap (2017), saíram do novo texto uma Emenda Aglutinativa Global à PEC n. 287-A/16, que foi resultante da aglutinação do texto original (governo) com o substitutivo adotado pela comissão especial e emendas, bem como todas as alterações que diziam respeito ao segurado especial (pequeno produtor rural), que continuará aposentando-se aos 60 anos de idade, se homem, e 55 anos, se mulher, ambos com 15 anos de tempo de contribuição; e continuará contribuindo a partir de um percentual sobre a comercialização de sua produção. As alterações no Benefício de Prestação Continuada (BPC) saíram do texto. E, assim, continua se garantindo o valor de 1 salário mínimo mensal aos portadores de deficiência e aos idosos que não possuam meios de prover a sua manutenção ou de tê-la provida por seus familiares.

Quanto às alterações no texto da emenda aglutinativa, foi informado que as contribuiç̧̃es sociais não serão mais submetidas à DRU. Acrescente-se que o tempo mínimo de contribuição para aposentadoria no Regime Geral de Previdência Social (RGPS) foi diminuído de 25 para 15 anos. No caso dos

10 No dia 28 de abril, cerca de 40 milhões de trabalhadores cruzaram os braços contra as reformas da Previdência e Trabalhista, bem como a Lei das Terceirizações que havia sido aprovada recentemente (Silva, 2018). 
servidores públicos, o tempo mínimo de contribuição para aposentadoria, no Regime Próprio de Previdência dos Servidores (RPPS), continuou em 25 anos.

O novo texto consolida a unicidade de tratamento entre servidores públicos e demais empregados, nos seguintes quesitos - com vigência a partir da publicação da PEC n. 287 - A-16: a) idades de aposentadoria equivalentes (sendo inclusive mais rígidas para o servidor público durante a fase de transição); b) regras equivalentes para pensão e acumulação de pensão; c) regras equivalentes para o cálculo dos benefícios por invalidez; d) fórmula de cálculo pela média das contribuições para servidores e demais empregados, inclusive para os servidores que entraram antes de 2003 (a não ser que se aposentem com 62/65 anos (DIAP, 2017).

Diante da mobilização das centrais sindicais anunciando uma greve geral para dezembro de 2017, o presidente da Câmara dos Deputados, Rodrigo Maia, transferiu a votação da reforma para o dia 19 de fevereiro de 2018 (Silva, 2018).

O Governo Federal buscou criar condições para aprovar a reforma da Previdência na Câmara dos Deputados, apresentando, em 7 de fevereiro, uma nova Emenda Aglutinativa Global à proposta em debate na Casa. Era um texto que reunia o texto original com o substitutivo adotado pela Comissão Especial e com as emendas apresentadas à PEC n. 287/2016.

Entre as principais alterações anunciadas pelo relator da PEC n. 287/16, deputado Arthur Oliveira Maia (PPS-BA), a Emenda beneficiava viúvo ou viúva de policial morto em atividade, que passariam a receber pensão integral e não mais percentual do salário, como na última versão apresentada no final de 2017. Com essa mudança, o governo pretendia obter o apoio de deputados da bancada da segurança pública. A mudança valeria para cônjuges de policiais rodoviários federais, policiais federais e policiais civis, exceto os policiais militares que ficaram da reforma da Previdência.

O texto mantinha os mesmos critérios da última emenda aglutinativa, como a exigência dos 25 anos de contribuição para aposentadoria dos servidores públicos. Estabelecia também a autorização para os governos federal, estaduais e municipais, contratarem, mediante licitação, planos de previdência complementar de entidades abertas de previdência complementar para seus servidores, numa clara concessão ao mercado privado de previdência. 
De resto fazia mudanças pontuais para avançar na conquista de votos para sua aprovação. De acordo com o DIAP (2018), o novo texto se resume a 4 pontos-chave: "1) a retirada de qualquer menção a trabalhadores rurais, 2) a garantia da manutenção do Benefício de Prestação Continuada, o chamado BPC, 3) a redução do tempo mínimo de contribuição de 25 para 15 anos no RGPS e 4) a inclusão do novo artigo que beneficia viúvas de policiais"11.

Com uma greve geral realizada pelas centrais sindicais e movimentos sociais no dia 19 de fevereiro, com paralisações e protestos em agências do Instituto Nacional do Seguro Social (INSS), em todo o país, os trabalhadores conseguiram pressionar o Governo Federal, que já havia recuado da votação tendo em vista que nenhuma alteração constitucional poderia ser votada em face da intervenção federal decretada sobre a segurança pública no Estado do Rio de Janeiro, que passou ao comando das Forças Armadas.

Para Santos (2017), a reforma retira da Previdência Social seu papel de garantia de renda para os trabalhadores e busca transferir a poupança previdenciária para o setor privado. Não será a sua substituição pelo sistema financeiro, que aumenta seus lucros dentro da mais grave crise econômica vivida pelo País, que assegurará ao trabalhador uma aposentadoria digna e sustentável.

\section{Conclusão}

A contrarreforma da Previdência e da Assistência Social apresentada em 2016 pelo governo federal, se aprovada, promoverá profunda regressão nas condições de vida da classe trabalhadora. Quem ganha com as modificações que foram propostas são os capitalistas hegemonizados pelo capital financeiro, com a abertura de mercado para a previdência privada e a manutenção dos lucros derivados do sistema da dívida pública. Observe-se que

11 Departamento Intersindical de Assessoria Parlamentar (DIAP). Governo apresenta nova Emenda Aglutinativa à reforma da Previdência. Brasília/DF, 7 fev. 2018. Disponível em: <http://www. diap.org.br/index.php/noticias/noticias/27861-governo-apresenta-nova-emenda-aglutinativa-a-reforma-da-previdencia>. Acesso em: 9 fev. 2018. 
o alongamento do tempo de contribuição permite a ampliação do exército industrial de reserva, pressionando os salários para baixo e, desse modo, proporciona o aumento da exploração do trabalhador para garantir a lucratividade do capitalismo dependente brasileiro.

As centrais sindicais de trabalhadores construíram greves gerais e mobilizações unificadas com os movimentos sociais da cidade e do campo que foram fundamentais para impedir que o desmonte da Previdência e da Assistência Social fosse aprovado pelo Congresso Nacional.

\section{Referências}

AUDITORIA CIDADÃ DA DÍVIDA. Orçamento Geral da União (Executado em 2015). Brasília, 2015. Disponível em: <http://www.auditoriacidada.org.br/wp-content/uploads/2013/08/ grafico-2015-2.pdf>. Acesso em: 13 fev. 2017.

BEHRING, Elaine Rossetti. Brasil em contra-reforma — desestruturação do Estado e perda de direitos. 2. ed. São Paulo: Cortez, 2008.

BRASIL. Presidência da República - Casa Civil - Subchefia para Assuntos Jurídicos. Lei Orgânica da Assistência Social. Disponível em: <http://www.planalto.gov.br/ccivil_03/ leis/L8742compilado.htm>. Acesso em: 7 dez. 2016.

BRASIL. Proposta de Emenda à Constituição n. 287/2016. Altera os arts. 37, 40, 109, 149, 167, 195, 201 e 203 da Constituição, para dispor sobre a seguridade social, estabelece regras de transição e dá outras providências. Brasília: Câmara dos Deputados, 2016. Disponível em: <http://www.camara.gov.br/proposicoesWeb/prop_mostrarintegra?codteor=1514975\&filename=PEC+287/2016>. Acesso em: 8 dez. 2016.

BRASIL. Constituição da República Federativa do Brasil. 19. ed. Brasília: Câmara dos Deputados, Coordenação de Publicações, 2002. (Texto constitucional de 5 de outubro de 1988, com as alterações adotadas pelas Emendas Constitucionais de n. 1, de 1992, a 38, de 2002, e pelas Emendas Constitucionais de Revisão de n. 1 a 6, de 1994).

CANO, W. Soberania política e econômica na América Latina. São Paulo: Unesp, 2000.

CPIPREV. Relatório Final. Senado Federal: Brasília, 2017. Disponível em: <http://www.contag.org.br/arquivos/portal/Relatorio\%20Final\%20CPIPREV.pdf>. Acesso em: 23 jan. 2018.

CHESNAIS, F. A Mundialização do Capital. São Paulo: Xamã, 1996.

DEPARTAMENTO INTERSINDICAL DE ASSUNTOS PARLAMENTARES (DIAP). Governo apresenta novo texto à reforma da Previdência. Brasília, 23 nov. 2017. Disponível em: <http://www.diap.org.br/index.php/noticias/agencia-diap/27710-governo-apresenta-novo-texto-da-reforma-da-previdencia>. Acesso em: 12 dez. 2017. 
DEPARTAMENTO INTERSINDICAL DE ESTATÍSTICA E ESTUDOS SOCIOECONÔMICOS (DIEESE); ASSOCIAÇÃO NACIONAL DOS AUDITORES FISCAIS DA RECEITA FEDERAL DO BRASIL (ANFIP). Previdência: reformar para excluir? Contribuição técnica ao debate sobre a reforma da previdência social brasileira - Brasília: DIEESE/ANFIP, 201748 p. (Documento síntese). Disponível em: <https://www.dieese.org.br/livro/2017/previdenciaSintese.html>. Acesso em: 19 jan. 2018.

DEPARTAMENTO INTERSINDICAL DE ESTATÍSTICA E ESTUDOS SOCIOECONÔMICOS (DIEESE). PEC n. 241/2016: o novo regime fiscal e seus possíveis impactos. DIEESE, São Paulo, 2016. (Nota Técnica n. 161).

DEPARTAMENTO INTERSINDICAL DE ESTATÍSTICA E ESTUDOS SOCIOECONÔMICOS (DIEESE). PEC n. 287: a minimização da Previdência pública. São Paulo: DIEESE, 2017. (Nota Técnica n. 168).

DRUMMOND, Carlos. Manipulações e desrespeito à Constituição ocultam saldos positivos da Previdência. Disponível em: <http://www.cartacapital.com.br/revista/904/o-deficit-e-miragem>. Acesso em: 9 dez. 2016.

FAGNANI, E. Previdência social: reformar ou destruir? In: JINKINGS, I.; DORIA, K., CLETO, Murilo (Orgs.). Por que gritamos golpe? São Paulo: Boitempo, 2016.

FATORELLI, M. L. Auditoria cidadã da dívida dos Estados. Brasília: Editora Inove, 2013. FAZIO, L. O que é Previdência Social. São Paulo: Loyola, 2016.

HARVEY, D. O enigma do capital e as crises do capitalismo. São Paulo: Boitempo, 2011.

JACOULD, L. A igualdade ainda é um valor a ser perseguido? In: OXFAM; Le Monde Diplomatique Brasil. Desigualdade em movimento, São Paulo, jan. 2017. Disponível em: https://www.oxfam.org.br/sites/default/files/arquivos/desigualdade_em_movimento.pdf. Acesso em: 14 fev. 2017.

MARX, K. Valor, trabalho e mais-valia. O confronto entre trabalho e capital. In: NETTO, J. P. (Org.). O leitor de Marx. Rio de Janeiro: Civilização Brasileira, 2012.

MINELLA, A. Elites financeiras, sistema financeiro e governo FHC. In: OURIQUES, N. D.; RAMPINELLI, W. J. (Orgs.). No fio da navalha. Crítica das reformas neoliberais de FHC. São Paulo: Xamã, 1997.

PETRAS, James. Brasil: a retirada dos direitos sociais e trabalhistas. In: PETRAS, James. Neoliberalismo: América Latina, Estados Unidos e Europa. Blumenau: Editora da FURB, 1999.

POCHMANN, M. Brasil sem industrialização: a herança renunciada. Ponta Grossa: Editora UEPG, 2016.

QUEIROZ, A. A. O que diz a reforma da Previdência do governo Temer. Disponível em: http://www.diap.org.br/index.php/noticias/agencia-diap/26586-o-que-diz-a-reforma-da-previdencia-do-governo-temer. Acesso em: 9 dez. 2016.

REDE BRASIL ATUAL (RBA). Centrais marcam novo protesto contra reforma da Previdência. São Paulo, 31 jan. 2018. Disponível em: <http://www.redebrasilatual.com.br/ trabalho/2018/01/centrais-marcam-novo-protesto-contra-reforma-da-previdencia>. Acesso em: 1 fev. 2018. 
SADER, E. Do Brasil que temos ao Brasil que queremos. In: SADER, Emir (Org.). O Brasil que queremos. Rio de Janeiro: LPP/UERJ, 2016.

SALVADOR, E. Ajuste fiscal e a captura do fundo público pelo capital portador de juros. In: RAMOS, Gustavo Teixeira... [et al.] (Orgs.). A classe trabalhadora e a resistência ao golpe de 2016. Bauru: Canal 6, 2016.

SALVADOR, E. Fundo público e seguridade social no Brasil. São Paulo: Cortez, 2010.

Fundo Público e o financiamento das Políticas Sociais no Brasil. Revista Serviço Social. Londrina, v. 14, n. 2, p. 504-22, jan./jun. 2012.

SANTOS, L. A. A Reforma da Previdência do Governo Temer e o Desmonte da Previdência Pública no Brasil. Apêndice: O Parecer da Comissão Especial da PEC n. 287 - Resumo das Principais Mudanças e seus Impactos. Brasília: DIAP, 16 de maio de 2017. Disponível em: <http://www.diap.org.br/images/stories/reforma_previdencia_governo_temer_apendice. pdf >. Acesso em: 7 jul. 2017.

SILVA, Maria Lúcia Lopes da. Trabalho e previdência social no Brasil no contexto da crise do capital. In: Revista O Social em Questão, Ano XVIII, n. 34. Rio de Janeiro: PUC-Rio, 2015.

SILVA, Mauri Antônio. A Contrarreforma da Previdência Social no Brasil: análise crítica da estratégia do capital financeiro e da resistência da classe trabalhadora. Trabalho de Conclusão de Curso (graduação) - Universidade Federal de Santa Catarina, Centro Socioeconômico, Curso de Serviço Social, Florianópolis, 2018.

SINGER, André; LOUREIRO, Isabel. As contradições do lulismo: a que ponto chegamos. 1. ed. São Paulo: Boitempo, 2016.

SOARES, L. T. O desastre social. Rio de Janeiro: Record, 2003.

VIEIRA JUNIOR, R. J. A. As inconstitucionalidades do "Novo Regime Fiscal" instituído pela PEC n. 55, de 2016 (PEC n. 241, de 2016, na Câmara dos Deputados). Boletim Legislativo. Núcleo de Estudos e Pesquisas da Consultoria Legislativa. 53. Senado Federal, novembro de 2016. Disponível em: <http://www12.senado.leg.br/publicacoes/estudos-legislativos/ tipos-de-estudos/boletins-legislativos/bol53>. Acesso em: 14 fev. 2017.

\section{Sobre o autor}

MAURi Antônio dA Silva - Doutor em Serviço Social.

E-mail: mauri.silva19@gmail.com 